\title{
An Investigation of the ICAPM in Japan: Evidence from the Tokyo Stock Exchange with a Review of International and Accounting Research
}

\author{
Chikashi Tsuji \\ Graduate School of Systems and Information Engineering, University of Tsukuba \\ 1-1-1 Tennodai, Tsukuba, Ibaraki 305-8573, Japan \\ E-mail: mail_sec_low@minos.ocn.ne.jp
}

Received: July 13, 2011 Accepted: August 01, $2011 \quad$ DOI: 10.5296/ijafr.v1i1.818

\begin{abstract}
After the recent US and international related literature review, this paper explores the state variables that are priced in the Intertemporal Capital Asset Pricing Model (ICAPM) in Japan. Deriving the time-varying covariance risks by using the multivariate Generalized Autoregressive Conditional Heteroskedasticity (GARCH) model, we analyze the ICAPM in the Tokyo Stock Exchange. Our empirical examinations clarify that in Japan, the time-varying covariance between the first difference of the seasonally adjusted Consumer Price Index and market return and the time-varying covariance between the first difference of the trading volume divided by Japanese Gross Domestic Product and market return are priced in Merton's ICAPM. Further, we discuss the prospect for asset pricing and accounting research by reviewing the recent combined studies.
\end{abstract}

Keywords: EGARCH-in-mean Model, GARCH Model, GARCH-in-mean Model, ICAPM, Multivariate GARCH Model. 


\section{Introduction}

The Intertemporal Capital Asset Pricing Model (ICAPM) was developed by Merton (1973), and some studies such as Anderson et al. (2009), Bali (2008), Brennan et al. (2004), Kapadia (2011), Lundblad (2007), Petkova (2006), and Pollet and Wilson (2010) examined this model in the US. Further, recently, several international related studies have emerged as we review in the later section. However, testing the pricing of this ICAPM has little been implemented in Japan. Therefore, the objective of this paper is to explore the priced factors in the ICAPM in Japan. We also aim to supply new international and accounting research information by adding the newest literature review.

The novel characteristics of this paper are as follows. First, we test the ICAPM using the similar analysis of Lundblad (2007), however, differently from Lundblad (2007), this paper focuses on the covariance risks rather than volatility risk. Second, we newly find the priced time-varying covariance risks, which are associated with the dynamics of Consumer Price Index (CPI) and trading volume. This is our most important contribution.

The reminder of this paper is organized as follows. Section 2 performs the literature review focusing on the US and international studies, and Section 3 concisely introduces Merton's ICAPM. Section 4 describes the data, and Section 5 demonstrates our empirical results. Section 6 documents the prospect for asset pricing and accounting research, and finally, Section 7 concludes the paper.

\section{Literature Review with International Perspective}

As we mentioned, testing the pricing of this ICAPM has little been implemented in Japan, thus we conduct the review of related existing studies from the international viewpoint. First, recently, Moerman and van Dijk (2010) tested the International Capital Asset Pricing Model of Adler and Dumas (1983) for France, Germany, Japan, the UK, and the US over the period from 1975 to 1998 and found evidence of statistically significant prices of inflation risk. In addition, Bali and Cakici (2010) showed that the world market risk was not, but country-specific total and idiosyncratic risks were significantly priced in an ICAPM framework by using the sample of 23 developed and 14 emerging markets. Further, using bilateral cross-country equity portfolio investment data and the measures of transaction costs for 36 countries, Thapa and Poshakwale (2010) evidenced that markets where transaction costs were lower attracted greater equity portfolio investments. Moreover, Ang et al. (2009) demonstrated that stocks with recent past high idiosyncratic volatility had low future average returns around the world by using the stock return data from 23 developed countries.

Furthermore, related studies for the US markets, Brennan et al. (2004) documented that the investment opportunity set in the ICAPM was completely described by the real interest rate and the Sharpe ratio in the US. In addition, Petkova (2006) insisted that in the US, the Fama-French factors of HML (High-minus-Low) and SMB (Small-minus-Big) were correlated with the variables that described investment opportunities of the ICAPM. Further, using the nearly two century history of U.S. equity market returns, Lundblad (2007) estimated a positive and statistically significant risk return tradeoff in the ICAPM. Moreover, 
Bali (2008) explored the time-series relation between expected returns and risk, and concluded that the risk-return coefficient was highly significant in the US. Furthermore, Anderson et al. (2009) measured risk via return volatility and uncertainty via the degree of disagreement of professional forecasters, and obtained stronger empirical finding for an uncertainty-return trade-off than for the traditional risk-return trade-off in the US. Further, recent study by Pollet and Wilson (2010) exhibited that the average correlation between daily stock returns predicted subsequent quarterly stock market excess returns in the US. Moreover, Kapadia (2011) demonstrated that in the US, exposure to aggregate distress risk was the underlying source of the premia for the Fama-French SMB and HML factors.

\section{Theory and Model}

Regarding Merton's ICAPM, Lundblad (2007) describes the model as follows:

$$
E_{t}\left[r_{M, t}-r_{f, t}\right]=\left[\frac{-J_{W W} W}{J_{W}}\right] \sigma_{M, t}^{2}+\left[\frac{-J_{W F}}{J_{W}}\right] \sigma_{M F, t},
$$

where $r_{M, t}$ denotes the market return, $r_{f, t}$ is the risk-free rate, $\sigma_{M, t}^{2}$ is the variance of market return, and $\sigma_{M F, t}$ denotes the covariance between state variables and market return. Further, $\left[-J_{W W} W / J_{W}\right]$ is investors' risk aversion, and $\left[-J_{W F} / J_{W}\right]$ is the coefficient adjusting market risk premium in response to the changes of $\sigma_{M F, t}$. Where $J(W(t), F(t), t)$ means the utility function that is related to $W(t)$ : investors' wealth and $F(t)$ : state variables. (The subscripts by $W$ and/or $F$ mean partial differentiations by them.)

Namely, for empirical examinations, Merton's ICAPM can be written more concisely as follows:

$$
r_{M, t}-r_{f, t}=\lambda_{M} \sigma_{M, t}^{2}+\lambda_{C} \sigma_{M F, t}+\varepsilon_{t}
$$

In this paper, to focus on the covariance risks, we first test the following model (3):

$$
r_{M, t}-r_{f, t}=\lambda_{C} \sigma_{M F, t}+\varepsilon_{t}
$$

where market return's conditional variance follows Generalized Autoregressive Conditional Heteroskedasticity (GARCH) $(1,1)$ model as (4):

$$
\sigma_{M, t}^{2}=\delta_{0}+\delta_{1} \varepsilon_{t-1}^{2}+\delta_{2} \sigma_{M, t-1}^{2}
$$

Next, as shown in model (2), we test the ICAPM more rigorously by including the market return's variance term. Where market return's conditional variance follows GARCH $(1,1)$ model (4) or Exponential Generalized Autoregressive Conditional Heteroskedasticity (EGARCH) $(1,1)$ model (5). Namely, we estimate the ICAPM (2) as GARCH-in-mean model or EGARCH-in-mean model. 


$$
\ln \left(\sigma_{M, t}^{2}\right)=\delta_{0}+\delta_{1}\left(\left|\frac{\varepsilon_{t-1}}{\sigma_{M, t-1}}\right|\right)+\delta_{2}\left(\frac{\varepsilon_{t-1}}{\sigma_{M, t-1}}\right)+\delta_{3} \ln \left(\sigma_{M, t-1}^{2}\right)
$$

In computing the time-varying covariances included in models (2) and (3), this paper uses the multivariate GARCH model.

\section{Data}

The sample period of the data set used in this paper is from April 1985 to December 2009. We first construct the market risk premium: $r_{M, t}-r_{f, t}$. Where $r_{M, t}$ denotes the market return, which is computed using Tokyo Stock Price Index (TOPIX) (from Tokyo Stock Exchange (TSE)), and $r_{f, t}$ denotes the one-month negotiable Certificate of Deposit (CD) rates (from Bank of Japan (BOJ)).

In addition, we construct the following five covariance variables, CDCPI, CDDY, CDEF, CDTERM, and CDMTVGDP by using DCPI, DDY, DEF, DTERM, and DMTVGDP, respectively. Where DCPI denotes the first difference of the inflation rate of the seasonally adjusted CPI (excluding foods and energy) (from the Statistics Bureau, Ministry of Internal Affairs and Communications), DDY is the first difference of the dividend yield of the TSE First Section (from TSE), DEF means the default spread between the long-term Nikkei Bond Index yields (from Nikkei, Inc.) and 10-year Japanese government bond yields (from Quick Corp.), DTERM denotes the first difference of the yield spread between the 10-year Japanese government bond yields (from Quick Corp.) and the one-month $\mathrm{CD}$ rates (from BOJ), and finally, DMTVGDP is the first difference of the trading volume of TSE (from TSE) divided by Japanese Gross Domestic Product (GDP) (from Government of Japan).

Then we compute five variables, CDCPI, CDDY, CDEF, CDTERM, and CDMTVGDP, which are the covariances between market return $r_{M, t}$ and DCPI, DDY, DEF, DTERM, and DMTVGDP, respectively. In computing these time-varying covariances, we use the multivariate GARCH model.

\section{Empirical Results}

\subsection{Variable Characteristics and Their Relations}

This subsection explains the characteristics of data and variable relations. First, Table 1 shows the descriptive statistics of the variables, DCPI, DDY, DEF, DTERM, and DMTVGDP. This table indicates that all variables are slightly positively skewed, and have excess kurtosis than the normal distribution. Except for DEF, we take the first difference of the raw variables since they have unit roots according to the Augmented Dickey-Fuller (ADF) tests. Next, Table 2 reports the correlations among the above five variables. Table 2 indicates that the five variables have little correlation each other.

\subsection{Base Tests}

The empirical results as to the ICAPM pricing are presented in Tables 3 to 5. Table 3 shows the results of our base tests of the ICAPM pricing in Japan, where model (3) and the GARCH 
model (4) are used. As explained, the model (3) includes only the covariance risks from the multivariate GARCH model. Table 3 displays that CDCPI (time-varying covariance between market return and the first difference of the seasonally adjusted CPI) and CDMTVGDP (time-varying covariance between market return and the first difference of the trading volume divided by GDP) are strongly priced in the ICAPM in Japan.

\subsection{Robustness Checks}

This subsection performs the robustness checks. First, Table 4 reports the results of the ICAPM estimations by exploiting the GARCH-in-mean model. Namely, we here include both variance term and covariance variables from the multivariate GARCH model in the ICAPM (2), and where market return's variance follows the GARCH $(1,1)$ model (4). Table 4 again reports that CDCPI and CDMTVGDP are strongly priced in the ICAPM in the TSE.

Furthermore, we conduct another robustness check using the EGARCH-in-mean model. That is, again we here include both variance term and covariance variables derived by the multivariate GARCH model in the ICAPM (2), and where market return's variance follows the EGARCH $(1,1)$ model (5). Again, Table 5 demonstrates that CDCPI and CDMTVGDP are strongly priced in the ICAPM in Japan. Thus we recognize that these two time-varying covariance risks are statistically significantly priced in the TSE in Japan regardless of the testing model types.

Table 1. Variables Descriptive Statistics

\begin{tabular}{lccccc}
\hline \multicolumn{5}{c}{ Results of April 1985 to December 2009 } \\
\hline Mean & DCPI & DDY & DEF & DTERM & DMTVGDP \\
Median & 0.046 & 0.004 & 0.218 & 0.002 & 0.010 \\
Maximum & 0.029 & 0.000 & 0.191 & -0.008 & 0.013 \\
Minimum & 1.115 & 0.420 & 1.497 & 1.128 & 1.818 \\
Std. Dev. & -0.361 & -0.380 & -0.572 & -1.349 & -2.084 \\
Skewness & 0.158 & 0.068 & 0.262 & 0.294 & 0.440 \\
Kurtosis & 1.669 & 0.469 & 1.139 & 0.022 & 0.085 \\
Observations & 11.332 & 10.805 & 7.409 & 6.288 & 6.434 \\
\hline
\end{tabular}

Table 2. Variables Correlation Coefficients

\begin{tabular}{lcc|c|c|c}
\hline \multicolumn{5}{c}{ Results of April 1985 to December 2009 } \\
\hline DCPI & DDY & DEF & DTERM & DMTVGDP \\
\hline DDY & 1.000 & & & & \\
DEF & 0.035 & 1.000 & & & \\
DTERM & -0.104 & -0.008 & 1.000 & & \\
DMTVGDP & 0.016 & -0.137 & -0.086 & 1.000 & \\
\hline
\end{tabular}


Table 3. Testing the ICAPM by GARCH Model

\begin{tabular}{|c|c|c|c|c|c|c|}
\hline \multicolumn{7}{|c|}{ Results of April 1985 to December 2009} \\
\hline & & Model 1 & Model 2 & Model 3 & Model 4 & Model 5 \\
\hline \multirow[t]{2}{*}{ CDCPI } & Coef. & $5.811^{* *}$ & & & & \\
\hline & $p$-value & 0.025 & & & & \\
\hline \multirow[t]{2}{*}{ CDDY } & Coef. & & 0.258 & & & \\
\hline & $p$-value & & 0.862 & & & \\
\hline \multirow[t]{2}{*}{ CDEF } & Coef. & & & 1.131 & & \\
\hline & $p$-value & & & 0.240 & & \\
\hline \multirow[t]{2}{*}{ CDTERM } & Coef. & & & & -0.357 & \\
\hline & $p$-value & & & & 0.693 & \\
\hline \multirow[t]{2}{*}{ CDMTVGDP } & Coef. & & & & & $0.901 * *$ \\
\hline & $p$-value & & & & & 0.033 \\
\hline LL & & -885.006 & -884.171 & -886.453 & -884.113 & -881.708 \\
\hline $\mathrm{SC}$ & & 6.055 & 6.070 & 6.065 & 6.070 & 6.054 \\
\hline
\end{tabular}

LL denotes Log likelihood and SC is Schwarz criterion. ** means the statistical significance at the 5\% level, and * means the statistical significance at the $10 \%$ level.

Table 4. Testing the ICAPM by GARCH-in-mean Model

\begin{tabular}{|c|c|c|c|c|c|c|}
\hline \multicolumn{7}{|c|}{ Results of April 1985 to December 2009} \\
\hline & & Model 1 & Model 2 & Model 3 & Model 4 & Model 5 \\
\hline \multirow[t]{2}{*}{ MV } & Coef. & 0.002 & 0.044 & 0.004 & 0.010 & $-0.046 * *$ \\
\hline & $p$-value & 0.860 & 0.200 & 0.726 & 0.465 & 0.009 \\
\hline \multirow[t]{2}{*}{ CDCPI } & Coef. & $5.790 * *$ & & & & \\
\hline & $p$-value & 0.027 & & & & \\
\hline \multirow[t]{2}{*}{ CDDY } & Coef. & & 5.698 & & & \\
\hline & $p$-value & & 0.185 & & & \\
\hline \multirow[t]{2}{*}{$\mathrm{CDEF}$} & Coef. & & & 1.174 & & \\
\hline & $p$-value & & & 0.243 & & \\
\hline \multirow[t]{2}{*}{ CDTERM } & Coef. & & & & -0.841 & \\
\hline & $p$-value & & & & 0.410 & \\
\hline \multirow[t]{2}{*}{ CDMTVGDP } & Coef. & & & & & $2.108^{* *}$ \\
\hline & $p$-value & & & & & 0.000 \\
\hline LL & & -884.990 & -883.232 & -886.384 & -883.861 & -879.169 \\
\hline $\mathrm{SC}$ & & 6.075 & 6.083 & 6.084 & 6.087 & 6.056 \\
\hline
\end{tabular}

LL denotes Log likelihood and SC is Schwarz criterion. ${ }^{* *}$ means the statistical significance at the $5 \%$ level, and * means the statistical significance at the $10 \%$ level. MV means market return's variance. 
Table 5. Testing the ICAPM by EGARCH-in-mean Model

\begin{tabular}{|c|c|c|c|c|c|c|}
\hline \multicolumn{7}{|c|}{ Results of April 1985 to December 2009} \\
\hline & & Model 1 & Model 2 & Model 3 & Model 4 & Model 5 \\
\hline \multirow[t]{2}{*}{ MV } & Coef. & -0.004 & -0.011 & -0.002 & 0.002 & $-0.053 * *$ \\
\hline & $p$-value & 0.749 & 0.719 & 0.850 & 0.860 & 0.003 \\
\hline \multirow[t]{2}{*}{ CDCPI } & Coef. & $5.768^{* *}$ & & & & \\
\hline & $p$-value & 0.027 & & & & \\
\hline \multirow[t]{2}{*}{ CDDY } & Coef. & & -1.026 & & & \\
\hline & $p$-value & & 0.790 & & & \\
\hline \multirow[t]{2}{*}{$\mathrm{CDEF}$} & Coef. & & & 1.032 & & \\
\hline & $p$-value & & & 0.299 & & \\
\hline \multirow[t]{2}{*}{ CDTERM } & Coef. & & & & -0.702 & \\
\hline & $p$-value & & & & 0.484 & \\
\hline \multirow[t]{2}{*}{ CDMTVGDP } & Coef. & & & & & $2.275^{* *}$ \\
\hline & $p$-value & & & & & 0.000 \\
\hline LL & & -871.213 & -880.421 & -882.786 & -880.263 & -874.298 \\
\hline $\mathrm{SC}$ & & 6.068 & 6.083 & 6.079 & 6.082 & 6.042 \\
\hline
\end{tabular}

LL denotes Log likelihood and SC is Schwarz criterion. ${ }^{* *}$ means the statistical significance at the $5 \%$ level, and * means the statistical significance at the $10 \%$ level. MV means market return's variance.

\section{Prospect for Asset Pricing and Accounting Research}

From the viewpoint of accounting measure, we used the dividend yield in this study although the covariance measure constructed by using it was not priced in the ICAPM in Japan. However, new studies combined two fields of asset pricing and accounting are recently increasing. Hence in this section, we review such studies and discuss the prospect for those combined research.

First, Kothari (2001) reviewed empirical research of the relationship between capital markets and financial statements. Kothari (2001) suggested that evidence from those studies was helpful for investment decisions in capital markets, accounting standard setting, and companies' financial disclosure decisions. In addition, Richardson et al. (2010) surveyed recent research in accounting anomalies and fundamental analysis, and Lewellen (2010) also surveyed literature and insisted that the literature of accounting anomalies and fundamental analysis provided significant insights into the stock price behavior and the relationship between accounting numbers and corporate value. Further, Bauman (1996), Hirshleifer (2001), Schwert (2003), and Subrahmanyam (2007) are also important literature review papers for us.

Next, in the context of risk and accounting anomalies, Khan (2008) documented that a considerable portion of cross-sectional variations in average stock returns to high and low accrual companies was explained by risk. In this study, ICAPM was used for the empirical 
examinations. Further, Core et al. (2008) conducted asset-pricing tests and reported that they obtained no evidence that accruals quality was a priced risk factor, while Francis et al. (2005) concluded that accruals quality was a priced risk factor.

Moreover, from the viewpoint of (accounting) information and market (in)efficiency, Mohanram and Rajgopal (2009) insisted that although Easley et al. (2002) documented that private information (PIN) was a determinant of stock returns, their replicated tests of Easley et al. (2002) indicated that while PIN does predict future returns in the same sample of Easley et al. (2002), the effect was not robust to alternative specifications and time periods. In addition, Ciftci and Cready (2011) found that the positive relation between the level of future earnings and Research and Development (R\&D) intensity increased with corporate size, and that the positive relation between the future earnings volatility and R\&D intensity declined with corporate size. Further, Jorgensen et al. (2011) found a positive association between aggregate stock returns and contemporaneous earnings dispersion. They also found a negative association between aggregate stock returns and future earnings dispersion. Furthermore, focusing on the quality of information, $\mathrm{Ng}$ (2011) found that higher information quality was related with lower liquidity risk and that the reduction in cost of capital because of this association was economically significant. He also found that the negative relation between information quality and liquidity risk was stronger when there exist large shocks to market liquidity.

Finally, with more comprehensive perspective, Lang and Maffett (2011) documented, for a global sample, that corporations with greater transparency, which is judged by earnings management, auditor choice, accounting standards, and so forth, showed less liquidity volatility, fewer extreme illiquidity events and lower correlations between firm-level liquidity and both market liquidity and market returns.

To sum up, from the combined viewpoint of asset pricing and accounting research, my review implies the following key points for the future combined research: (1) discriminating of risk factors in asset pricing and accounting return anomalies; (2) applying the testing methodology of asset pricing to accounting empirical research; (3) inferring investors' psychological perceptions of the process of earnings and excess return generation; (4) using accounting information for testing market (in)efficiency and for scrutinizing the information quality as to financial statements; and (5) improving the fundamental analysis-based trading strategies for practitioners engaged in investment businesses. As above, combined research of asset pricing and accounting are being important since it provides considerable benefits for academics, standard setters, and practitioners by leading them to deeper understanding of accounting information, market (in)efficiency, capital markets' behavior, investors' psychological aspects, and information quality of financial statements.

\section{Summary and Conclusions}

This paper investigated the priced state variables in the ICAPM in Japan. Differently from the US previous study by Lundblad (2007), this paper focused on the time-varying covariance risks from the multivariate GARCH model. As a result, our empirical studies obtained the following interesting new evidence. 
First, for the TSE in Japan, we found that the time-varying covariance between the first difference of the seasonally adjusted CPI and market return was one of the important priced state variables in the ICAPM.

In addition, the time-varying covariance between the first difference of the trading volume divided by GDP and market return was also the strongly priced state variable in Merton's ICAPM in Japan. These two variables' statistical significances were robust regardless of the model types.

The above new robust evidence derived in this paper will contribute not only to the body of academic researches of asset pricing in finance but also to the area of accounting. Our newest international literature review both of asset pricing and accounting fields also contributes to update the related knowledge and understanding of international academic researchers and practitioners engaged in accounting and finance. We consider that future related works exploiting international data sets including accounting data will be valuable. These works will lead to more worldwide conclusions, and these are our future task.

\section{Acknowledgements}

The author acknowledges the generous financial assistance of the Japan Society for the Promotion of Science. Further, I thank an anonymous referee for the constructive comments to improve this paper. I greatly appreciate the invitation of the Editors to write to this new journal.

\section{References}

Adler, M., \& Dumas, B. (1983). International portfolio choice and corporation finance. A synthesis. Journal of Finance, 38, 925-984.

Anderson, E. W., Ghysels, E., \& Juergens, J. L. (2009). The impact of risk and uncertainty on expected returns. Journal of Financial Economics, 94, 233-263.

Ang, A., Hodrick, R. J., Xing, Y., \& Zhang, X. (2009). High idiosyncratic volatility and low returns: International and further U.S. evidence. Journal of Financial Economics, 91, 1-23.

Bali, T. G. (2008). The intertemporal relation between expected returns and risk. Journal of Financial Economics, 87, 101-1314.

Bali, T. G., \& Cakici, N. (2010). World market risk, country-specific risk and expected returns in international stock markets. Journal of Banking and Finance, 34, 1152-1165.

Bauman, M. (1996). A review of fundamental analysis research in accounting. Journal of Accounting Literature, 15, 1-33.

Brennan, M. A., Wang, A. W., \& Xia, Y. (2004). Estimation and test of a simple model of intertemporal capital asset pricing. Journal of Finance, 4, 1743-1775.

Ciftci, M., \& Cready, W. M. (2011). Scale effects of R\&D as reflected in earnings and returns. Journal of Accounting and Economics, 52, 62-80.

Core, J. E., Guay, W. R., \& Verdi, R. (2008). Is accruals quality a priced risk factor? Journal of Accounting and Economics, 46, 2-22. 
Easley, D., Hvidkjaer, S., \& O'Hara, M. (2002). Is information risk a determinant of asset returns? Journal of Finance, 57, 2185-2221.

Engle, R. F., \& Kroner, K. F. (1995). Multivariate simultaneous generalized ARCH. Econometric Theory, 11, 122-150.

Francis, J., LaFond, R., Olsson, P., \& Schipper, K. (2005). The market pricing of accruals quality. Journal of Accounting and Economics, 39, 295-327.

Hirshleifer, D. (2001). Investor psychology and asset pricing. Journal of Finance, 56, 1533-1597.

Jorgensen, B., Li, J., \& Sadka, G. (2011). Earnings dispersion and aggregate stock returns. Journal of Accounting and Economics, forthcoming.

Kapadia, N. (2011). Tracking down distress risk. Journal of Financial Economics, forthcoming.

Khan, M. (2008). Are accruals mispriced? Evidence from tests of an Intertemporal Capital Asset Pricing Model. Journal of Accounting and Economics, 45, 55-77.

Kothari, S. P. (2001). Capital markets research in accounting. Journal of Accounting and Economics, 31, 105-231.

Kroner, K. F., \& Ng, V. K. (1998). Modeling Asymmetric Comovement of Assets Returns. Review of Financial Studies, 11, 817-844.

Lang, M., \& Maffett, M. (2011). Transparency and Liquidity Uncertainty in Crisis Periods. Journal of Accounting and Economics, forthcoming.

Lewellen, J. (2010). Accounting anomalies and fundamental analysis: Analternative view. Journal of Accounting and Economics, 50, 455-466.

Lundblad, C. (2007). The risk return tradeoff in the long run: 1836-2003. Journal of Financial Economics, 85, 123-150.

Merton, R. C. (1973). An intertemporal capital asset pricing model. Econometrica, 41, 867-887.

Moerman, G. A., \& van Dijk, M. A. (2010). Inflation risk and international asset returns. Journal of Banking and Finance, 34, 123-150.

Mohanram, P., \& Rajgopal, S. (2009). Is PIN priced risk? Journal of Accounting and Economics, 47, 226-243.

$\mathrm{Ng}$, J. (2011). The effect of information quality on liquidity risk. Journal of Accounting and Economics, forthcoming.

Petkova, R. (2006). Do the Fama-French Factors Proxy for Innovations in Predictive Variables? Journal of Finance, 61, 581-612.

Pollet, J. M., \& Wilson, M. (2010). Average correlation and stock market returns. Journal of Financial Economics, 96, 364-380.

Richardson, S., Tuna, I., \& Wysocki, P. (2010). Accounting anomalies and fundamental analysis: A review of recent research advances. Journal of Accounting and Economics, 50, 410-454. 


\section{I Macrothink}

International Journal of Accounting and Financial Reporting

ISSN 2162-3082

Schwert, G. W. (2003). Anomalies and market efficiency. In: Constantinides, G. M., Harris, M., Stulz., R. (Eds.), Handbook of the Economics of Finance. Elsevier Science B. V., Netherlands (Chapter15).

Subrahmanyam, A. (2007). Behavioral finance: a review and synthesis. European Financial Management, 14, 12-29.

Thapa, C., \& Poshakwale, S. S. (2010). International equity portfolio allocations and transaction costs. Journal of Banking and Finance, 34, 2627-2638. 